\title{
Provision and Costs of Ancillary Services in a Restructured Electricity Market
}

\author{
Adelino J. C. Pereira ${ }^{(1)}$, Zita A. Vale ${ }^{(2)}$, A. Machado e Moura ${ }^{(3)}$ \\ and J. A. Dias Pinto ${ }^{(1)}$ \\ ${ }^{1}$ Instituto Superior de Engenharia de Coimbra, Department of Electrical Engineering, Rua Pedro Nunes, \\ Quinta da Nora, 3030-199 Coimbra, Portugal. phone : +351 239790 200, \\ fax: +351 239790 201, e-mail:ajcp@isec.pt, jpinto@isec.pt \\ ${ }^{2}$ Instituto Superior de Engenharia do Porto, Department of Electrical Engineering, Rua Dr. António \\ Bernardino de Almeida, 431-4200-072 Porto, Portugal. phone : +351 228340 500, \\ fax: +351 228821 159, e-mail:zav@dee.isep.ipp.pt \\ ${ }^{3}$ Faculdade de Engenharia da Universidade do Porto, Department of Electrical Engineering \\ R. Dr. Roberto Frias, 4200-465 Porto, Portugal. phone : +351 225081 819, \\ fax: +351 225081 440, e-mail:mmoura@fe.up.pt
}

\begin{abstract}
Power industry has been experiencing dramatic changes from a vertically integrated industry into a deregulated competitive electricity market over the last decade. In a restructured electricity industry, markets govern the operation and expansion of electricity generation, and power plants make profits from markets for energy and ancillary services. In the last years there has been a worldwide trend toward restructuring the electricity supply industry and consequently energy markets were created. Ancillary services are defined as all those activities on the interconnected grid that are necessary to support the power transmission and withstand the security operation as well as the power quality level.

This paper presents the most important ancillary services provided by the independent system operator in a restructured power system. It will be also described the Simultaneous Optimisation algorithm to performer the active power reserves dispatch in a competitive environment.
\end{abstract}

\section{Key words}

Ancillary Services; Electricity Markets, Power Quality, Simultaneous Optimisation Algorithm.

\section{Introduction}

Currently, electric power systems all over the world are moving from a regulated environment based upon traditional vertically integrated utilities toward a more decentralized environment based on a much greater extent upon competitive markets. Therefore, it is required to address the issues related to remuneration and charges of electrical services in this new and, in many instances, still unknown world, in order to assure the technical and economical power system feasibility[1,2].

Ancillary services are those services provided by the equipment in the system and generators that generate, control, and transmit electricity in support of the basic services of generating capacity, energy supply, and power delivery. These services are required to ensure that the system operators are able to meet their responsibilities[3]. In order to maintain the system in a secure operating state, the system operator must be able to:

- Control the frequency of the system within certain bounds;

- control the voltage profile of the system within certain bounds;

- maintain the stability of the system;

- $\quad$ prevent overloads in the transmission system;

- restore the system or portions of the system when and if required.

Since most of these services are provided by generating units, however, it should be possible to create competitive markets for the provision, acquisition, and pricing of these services. Usually Competitive markets are attractive, since competition control the price, promotes efficiency, and yields new ways to meet customer requirements[2]. The price for ancillary services in a competitive markets reflect opportunity costs and operating costs. The costs for these services are not trivial, on the order of 5 to $10 \%$ of the cost of the energy commodity[4].

The ability of the power system to supply electricity securely is essential to the operation of the electricity market. The electricity market has to follow the physical power system constraints as well as the market rules aimed at maximum profit for suppliers, lower prices for consumers and an overall maximum social welfare[3].

The main characteristic of the ancillary services discussed in this paper is that capacity reserved and procured in advance and then incremental energy is dispatched in response to real time unbalances. This means that there are two relevant prices to be paid to the generators. On is the price paid for reserved capacity and 
other is the price paid for energy that is dispatched under certain defined conditions[5].

\section{Ancillary Services Overview}

For the electric power system to remain in a secure operating state, sufficient ancillary services must be available to respond to credible contingency events and return the power system to a satisfactory operating point in which frequency, voltages, stability and network loading parameters are within specified limits. The precise level of reliability and availability that an operator is required to attain must be established beforehand and in a way that is economically sensible[6].

The ways in which ancillary services can be procured by the operator are: (a) By ownership of the equipment necessary to provide the service. This is the practical means of providing the services in many cases, such as for example the ownership of shunt capacitors and other reactive power devices. (b) By contracting with ancillary service providers for long-term provision of these services under specific terms and conditions. (c) By creating a market for the supply of services, where parties interested in providing the services bid for the right to provide the service. The bidders often will be the same parties that are engaged in the provision of the primary energy services[4].

\section{A. Frequency Control and Active Power Reserves}

Frequency regulation plays a very important role in power system security. This system strategy is a technique to maintaining a balance between generation and load on a minute-to-minute basis within a control area. The frequency deviation shall normally be within a specified acceptable range. The time deviation between synchronous time and real time is also normally controlled.

The reserve requirements arise from many causes. Reserves are needed for maintaining the integrity of the transmission system if some contingencies occur. Reserves are established to respond to uncertainties, but the main two are generation outages and load variations. To the extent that no generators are outages and all loads are constant, no reserves are required. However, if a generator outage occurs, it gives rise to a specific amount of needed reserves. If the generator outages frequently, the amount of reserves needed does not change, but the use of the reserves increases. However, when dealing with the probability of multiple outages, more frequent outages by a generating unit increase the amount of reserves needed to attain a specified reliability level.

One of the most important techniques for measuring and pricing reserve services has to do with opportunity costs. In general, a generating unit will have a choice between staying off line or coming on-line at minimum power. Alternatively, the same unit can come on line and provide a maximum amount of power. It has been observed, for example, that highly efficient (low operating cost) units are generally best off if they operate at full power.
However, less efficient units that are able to change their output are often better off operating at least partially as reserve units[7].

Frequency control can be obtained by the system operator from the following sources[4]:

- Automatic generation control within generating units, that is, the generators provide the system with prescribed amounts of frequency droop and change their output in accordance with changes in system frequency within a prescribed band of frequencies;

- obtaining the ability to obtain direct control of the power output of specific generating units;

- obtaining the ability to control or shed the load demand.

For a generator, the costs of providing active power reserves is different for thermal and Hydro systems. In general the components are investment costs, operational costs to keep the reserve stand by, operational costs when the service is activated, cost of non-optimal generation dispatch and investment cost for power capability normally not used for energy production.

Usually, frequency control can also be attained by sending appropriate price signals to generators. Consequently this strategy may voluntarily adjust their energy production and/or consumption based on these signals.

\section{B. Voltage control and Reactive Power Reserves}

Voltage control is achieved by generating or absorbing reactive power. Network power flows create voltage increases and/or drops. These phenomena results from the interactions between the inductances and capacitances of the network devices. Therefore, in order to maximize the amount of real power that can be transferred over a network reactive-power flows must be minimized. Voltage control requirements are location dependent, since the technical limits are inherent to the reactive power flow. The transmission planning process determines the reactive requirements in various areas of the network. These requirements are considered for a range of power system operating conditions including credible contingencies[8].

The reason why voltage control is required in systems includes[9]:

- In order that a power system operates safely, voltages must always be within the acceptable design range for each device. Voltages out of the bounder limits should be avoided.

- Voltages affect the flow of reactive power in the grid. Changes in the flows of reactive power have a strong influence on system losses. Thus, adjusting voltages can have significant effect on losses.

- Voltages and reactive power injections have a direct impact on the transfer capability of the system. Under some conditions, reactive power injections can have a 
significant impact on the ability of the system to deliver power between one region and another. Inability to deliver power between regions creates congestion.

The means by which reactive power can be delivered to the system include the following[9]:

- Generators, their speed of response is fast, and their ability to support voltage under extreme conditions is very good as well all synchronous generators present some capability to adjust their reactive power injection, but generators can be specified to have larger or smaller reactive power capability;

- Synchronous condensers.

- Capacitors, this is generally the cheapest way to provide reactive power.

- Shunt Reactors. In effect the opposite of capacitors. They are designed to absorb reactive power and tend to hold voltages down.

- Static VAR compensators. Expensive but fast. Under extreme conditions the reactive power capability drops as the square of the voltage.

- STATCOM compensators. Even more expensive and fast. Under extreme conditions, the reactive power drops linearly with the voltage, which makes them better that capacitors or Static VAR devices.

- Distributed generation sources. These devices are, in effect, small generators, and have many of the same features of generators.

The reactive devices have different characteristics in terms of dynamics and speed of response, ability of voltage changes, capital costs, operating costs, and opportunity costs. For example, synchronous generators are very fast reactive support devices, but have high opportunity costs if real-power output has to be reduced to produce more reactive power. Opportunity cost of reactive power is the benefit or profit that could otherwise be harnessed, but is given up by the reactive power supplier in order to generate reactive power. On the other hand, capacitors present a slow and have poor performance, although they are cheap to install and operate[3].

The reactive power providers can enter into either long or short-term contracts with the Independent System operator-ISO for reactive power provision. Contracted provisions involve payments to be made by the ISO, and it remains the main goal of the ISO to procure the service so as to minimize the total payment while meeting the system constraints. Although this is a seemingly fair enough objective, such an optimal selection can result in increased losses in the system or may require curtailment of real power transaction contracts, both of which are undesirable.

The main potential benefit of unbundling reactive power service is that, by making costs more transparent, it may encourage greater efficiencies in the provision and use of reactive power. On the other hand, an important constraint on the manner of unbundling is that reactive power supply is generally not competitive, at least in the short run.

\section{Service Blackstart}

The requirement for system restart is to provide at least two independent restart sources for each region, at least one of which is to be a fast restart source. The sources must be capable of initiating a restart of the main power system[10]. The main function of system blackstart is to restore the power system.

The blackstart capability is the ability of a control area to recover from a major system outage in a prompt, safe, and orderly fashion. The system operator must develop, test, train people for, and coordinate the implementation of a blackstart plan. The key resource for recovery is generating units that can go from a shutdown condition to an operating condition without support from the electrical system. This capability is essential during large-scale blackouts and islanding, since such units can start themselves and then produce power that can be used to energize the grid and provide power to start other generating units.

Implementation of a blackstart plan involves: first determining the nature and extent of the outage and whether the blackstart plan should be implemented; communicating with appropriate utility departments and with neighbouring utilities, the regional reliability council, public officials, and the public; disconnecting loads and sectionalizing the transmission grid; starting blackstart generating units; using load to maintain the generation/load balance and stabilize the on-line generators; energizing sections of the transmission system; providing service to critical facilities (e.g., nuclear plants, key substations, and generators without blackstart capability); coordinating the restart of nonblackstart-capable generators and using these to continue system restoration; reconnecting islands; and restoring service to remaining customer loads. All these steps must be implemented in a way that protects equipment and personnel, and maintains voltages and frequency near their specified reference values.

The cost of service blackstart presents four components[10]:

- Costs associated with blackstart units themselves. These include capital costs, testing costs, training costs, and fuel plus labor costs during actual blackstart operations.

- Transmission-system costs, including capital costs, planning and engineering costs, training costs, and personnel costs during an actual event.

- System-control costs, including capital costs and operating costs for planning, testing, and training.

- Costs at non-blackstart power plants to enable them to restart quickly once offsite power is restored as well as equipment damage costs incurred during an actual event that results from returning to service too quickly. 


\section{Simultaneous Optimization Algorithm}

The Simultaneous Optimization Method is one of the optimal approaches that can be used to perform the ancillary services dispatch in a competitive electricity market. This mathematical formulation allows the system operator to procure regulation down and up, spin reserve, non-spin reserve to a Day-Ahead. Any agents representing generating units or loads may bid into these markets. The bids include information for each of the 24 hours of the trading day[11, 12].

The main gal of the Simultaneous Optimization algorithm is to minimize the sum of ancillary service costs over a prescribed settlement interval. Usually the settlement interval is one hour for forward markets.

The mathematical formulation using this optimal technique can be descried as follows:

Min

$$
\sum_{K=2}^{4} \sum_{i=1}^{N}\left(P R_{i, k}+p \cdot P E_{i, k}\right) * X_{i, k}
$$

Suj: $\quad \sum_{i=1}^{N} X_{i, 2}=Q_{2}$

$$
\sum_{i=1}^{N} X_{i, 3}=Q_{3}
$$

$\sum_{i=1}^{N} X_{i, 4}=Q_{4}$

$\sum_{k=2}^{4} X_{i, K} \leq$ Cmáx $_{i} \quad \mathrm{i}=1, \ldots, \mathrm{N}$

$0 \leq X_{i, K} \leq C_{i, k}$ and $X_{i, K} \quad$ integer

Where:

$N$ - total number of bids;

$i$ - bid index $(i=1,2, \ldots, N)$ $k$ - ancillary service index ( $k=1$ for regulation down,

2 regulation up, 3 for spin, and 4 for non-spin);

$Q k$ - total capacity requirement for ancillary service $k$;

Cmaxi - maximum capacity of bid i;

$X_{i, k}$ - capacity bid of resource $i$ for ancillary service $k$;

$P R i, k$ price bid reserve of bid $i$ for ancillary service $k$;

$P E_{i, k}$ price bid energy of bid $i$ for ancillary service $k$;

$p$ - probability of utilization of bid $i$ for ancillary service $k$;

Figure 1 presents a summarized flow-chart of the Simultaneous Optimization Algorithm.

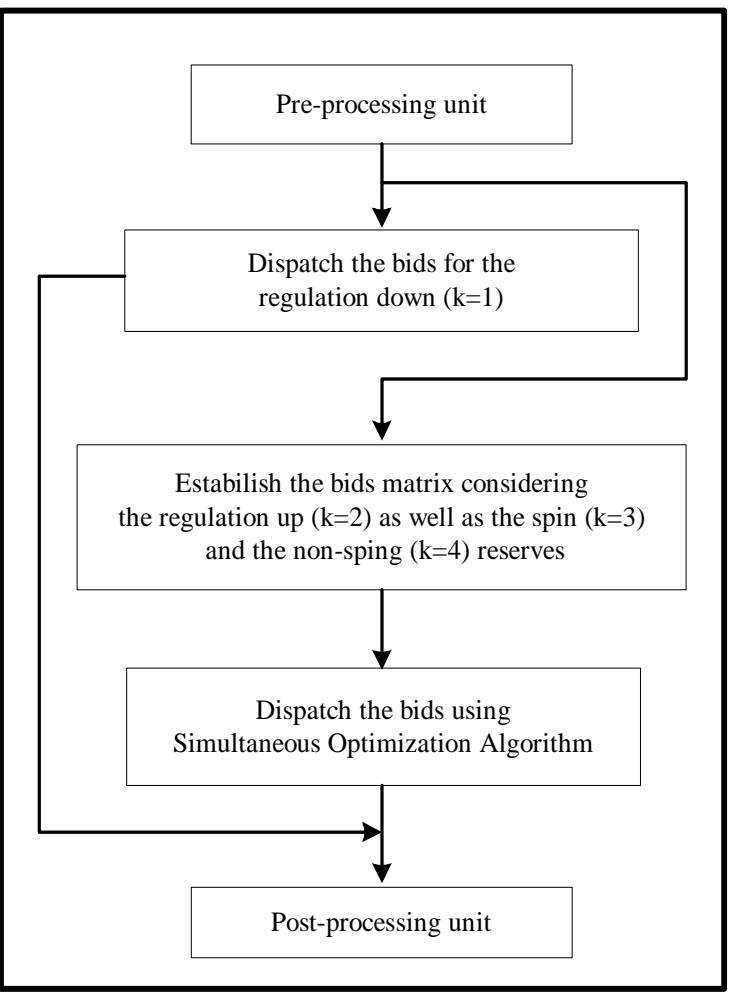

Fig. 1. Flow char of the Simultaneous Optimization Algorithm

\section{Application Examples}

In figure 2 it is shown the delay load diagram of the electric nower svstem.

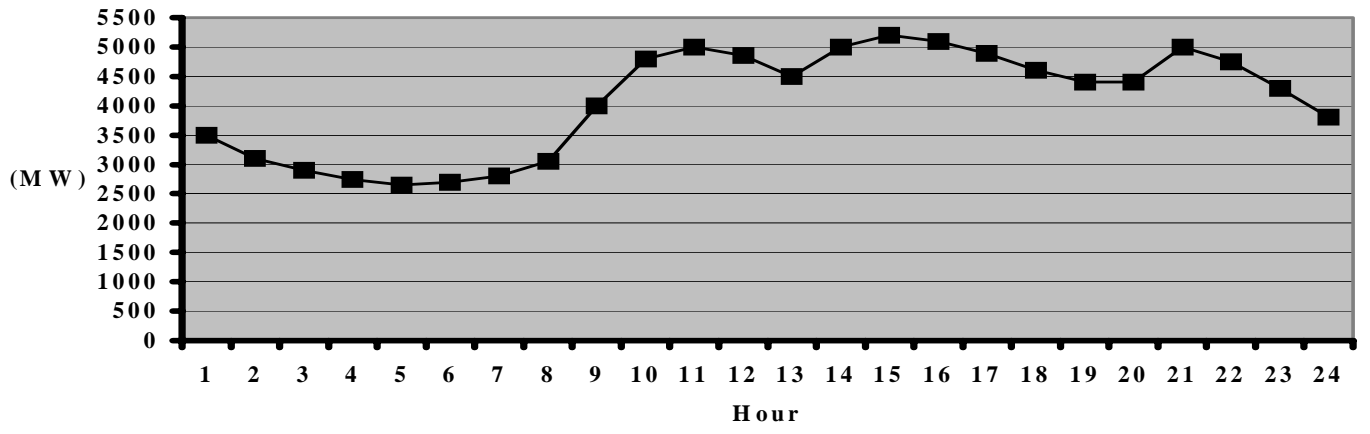

Fig. 2. Delay load diagram of the electric power system 
Table I presents the power requirement of the ancillary services.

TABLE I. - Power reserve requirements

\begin{tabular}{|c|c|c|c|c|c|}
\hline \multirow{3}{*}{ Hour } & \multicolumn{5}{|c|}{ Ancillary Services } \\
\cline { 2 - 6 } & $\begin{array}{c}\text { Regulation } \\
\text { Down }\end{array}$ & $\begin{array}{c}\text { Regulation } \\
\text { Up }\end{array}$ & $\begin{array}{c}\text { Spining } \\
\text { Reserve }\end{array}$ & $\begin{array}{c}\text { Non-Spin } \\
\text { Reserve }\end{array}$ & $\begin{array}{c}\text { Max. } \\
\text { Power }\end{array}$ \\
\cline { 2 - 6 } MW & MW & MW & MW & MW \\
\hline 1 & 102 & 170 & 90 & 68 & 430 \\
\hline 2 & 93 & 93 & 80 & 62 & 328 \\
\hline 3 & 87 & 87 & 77 & 58 & 309 \\
\hline 4 & 84 & 84 & 74 & 56 & 298 \\
\hline 5 & 81 & 81 & 73 & 54 & 289 \\
\hline 6 & 150 & 90 & 73 & 60 & 373 \\
\hline 7 & 165 & 96 & 80 & 64 & 405 \\
\hline 8 & 200 & 120 & 86 & 80 & 486 \\
\hline 9 & 242 & 145 & 100 & 97 & 584 \\
\hline 10 & 150 & 150 & 117 & 100 & 517 \\
\hline 11 & 150 & 150 & 120 & 100 & 520 \\
\hline 12 & 144 & 144 & 120 & 96 & 504 \\
\hline 13 & 230 & 138 & 116 & 92 & 576 \\
\hline 14 & 250 & 150 & 112 & 100 & 612 \\
\hline 15 & 156 & 156 & 120 & 104 & 536 \\
\hline 16 & 153 & 153 & 123 & 102 & 531 \\
\hline 17 & 150 & 250 & 122 & 100 & 622 \\
\hline 18 & 138 & 230 & 120 & 92 & 580 \\
\hline 19 & 135 & 225 & 112 & 90 & 562 \\
\hline 20 & 225 & 225 & 110 & 90 & 657 \\
\hline 21 & 242 & 242 & 110 & 97 & 691 \\
\hline 22 & 141 & 235 & 117 & 94 & 587 \\
\hline 23 & 129 & 215 & 114 & 86 & 544 \\
\hline 24 & 120 & 200 & 105 & 80 & 505 \\
\hline Total & 3597 & 3829 & 2471 & 2022 & 12046 \\
\hline & & & & & \\
\hline
\end{tabular}

In order to illustrate the mathematical application of the Simultaneous Optimization Algorithm it was selected the 14 hour of delay load diagram. Table II shows the ancillary services bids and the active power reserve requirements.

TABLE II. - Ancillary service bids and the active power reserve requirements

\begin{tabular}{|c|c|c|c|c|c|}
\hline \multirow{3}{*}{ Hour } & \multicolumn{5}{|c|}{ Ancillary Services } \\
\cline { 2 - 6 } & $\begin{array}{c}\text { Regulation } \\
\text { Down }\end{array}$ & $\begin{array}{c}\text { Regulation } \\
\text { Up }\end{array}$ & $\begin{array}{c}\text { Spin } \\
\text { Reserve }\end{array}$ & $\begin{array}{c}\text { Non-Spin } \\
\text { Reserve }\end{array}$ & $\begin{array}{c}\text { Max. } \\
\text { Power }\end{array}$ \\
\cline { 2 - 6 } & MW & MW & MW & MW & MW \\
\hline 1 & 30 & 25 & 30 & 40 & 60 \\
\hline 2 & 45 & 40 & 45 & 50 & 60 \\
\hline 3 & 35 & 20 & 40 & 40 & 50 \\
\hline 4 & 25 & 25 & 35 & 35 & 50 \\
\hline 5 & 40 & 30 & 50 & 50 & 55 \\
\hline 6 & 20 & 40 & 30 & 20 & 40 \\
\hline
\end{tabular}

\begin{tabular}{|c|c|c|c|c|c|}
\hline 7 & 35 & 35 & 45 & 45 & 35 \\
\hline 8 & 40 & 40 & 40 & 45 & 70 \\
\hline 9 & 30 & 25 & 35 & 35 & 65 \\
\hline 10 & 35 & 40 & 40 & 40 & 60 \\
\hline 11 & 25 & 30 & 35 & 40 & 50 \\
\hline 12 & 40 & 40 & 50 & 50 & 55 \\
\hline 13 & 45 & 30 & 45 & 55 & 55 \\
\hline 14 & 25 & 25 & 35 & 35 & 50 \\
\hline 15 & 35 & 30 & 30 & 40 & 50 \\
\hline 16 & 40 & 30 & 40 & 40 & 35 \\
\hline Total & $\mathbf{2 5 0}$ & $\mathbf{1 5 0}$ & $\mathbf{1 1 2}$ & $\mathbf{1 0 0}$ & $\begin{array}{c}\text { Total } \\
\mathbf{6 1 2}\end{array}$ \\
\hline
\end{tabular}

Table III presents the Bid prices of the ancillary services reserves.

TABLE III. - Bid prices of the ancillary services reserves

\begin{tabular}{|c|c|c|c|c|c|c|c|c|}
\hline \multirow{4}{*}{ Bids } & \multicolumn{8}{|c|}{ Ancillary Services } \\
\hline & \multicolumn{2}{|c|}{$\begin{array}{l}\text { Regulation } \\
\text { Down }\end{array}$} & \multicolumn{2}{|c|}{$\begin{array}{c}\text { Regulation } \\
\text { Up }\end{array}$} & \multicolumn{2}{|c|}{ Spin Reserve } & \multicolumn{2}{|c|}{$\begin{array}{c}\text { Non-Spin } \\
\text { Reserve }\end{array}$} \\
\hline & $V_{R}$ & $V_{E}$ & $V_{R}$ & $V_{E}$ & $\mathbf{V}_{\mathbf{R}}$ & $\mathbf{V}_{\mathbf{E}}$ & $\mathbf{V}_{\mathbf{R}}$ & $\mathbf{V}_{\mathrm{E}}$ \\
\hline & $\mathrm{Um} / \mathrm{MW}$ & $\mathrm{Um} / \mathrm{MWh}$ & $\mathrm{Um} / \mathrm{MW}$ & $\mathrm{Um} / \mathrm{MWh}$ & $\mathrm{Um} / \mathrm{MW}$ & $\mathrm{Um} / \mathrm{MWh}$ & $\mathrm{Um} / \mathrm{MW}$ & Um/MWl \\
\hline 1 & 3.7 & 45.3 & 5.6 & 45.3 & 6.6 & 42.5 & 6.5 & 42.5 \\
\hline 2 & 3.8 & 47.0 & 6.8 & 47.0 & 5.0 & 47.0 & 5.3 & 47.0 \\
\hline 3 & 4.3 & 45.9 & 5.6 & 45.9 & 6.2 & 41.4 & 5.2 & 41.4 \\
\hline 4 & 4.3 & 48.5 & 5.5 & 48.5 & 7.0 & 44.3 & 6.0 & 44.3 \\
\hline 5 & 4.2 & 44.4 & 4.3 & 44.4 & 4.6 & 46.0 & 5.0 & 46.0 \\
\hline 6 & 4.5 & 45.7 & 4.9 & 45.7 & 3.8 & 44.8 & 3.5 & 44.8 \\
\hline 7 & 4.7 & 46.3 & 4.5 & 46.3 & 5.4 & 45.0 & 6.0 & 45.0 \\
\hline 8 & 3.6 & 44.5 & 6.2 & 44.5 & 4.2 & 41.5 & 5.0 & 41.5 \\
\hline 9 & 4.0 & 43.2 & 5.2 & 43.2 & 4.0 & 41.0 & 3.0 & 41.0 \\
\hline 10 & 4.3 & 48.6 & 4.3 & 48.6 & 4.0 & 46.0 & 7.0 & 46.0 \\
\hline 11 & 3.2 & 47.5 & 4.8 & 47.5 & 5.0 & 47.0 & 5.0 & 47.0 \\
\hline 12 & 3.8 & 47.0 & 5.6 & 47.0 & 6.8 & 44.5 & 7.0 & 44.5 \\
\hline 13 & 3.8 & 46.8 & 5.2 & 46.8 & 6.8 & 41.0 & 6.8 & 41.0 \\
\hline 14 & 4.3 & 41.6 & 5.5 & 41.6 & 7.0 & 43.3 & 6.0 & 43.3 \\
\hline 15 & 5.0 & 46.5 & 5.2 & 46.5 & 6.0 & 45.4 & 5.0 & 45.4 \\
\hline 16 & 3.7 & 44.2 & 4.5 & 44.2 & 5.4 & 42.3 & 6.0 & 42.3 \\
\hline
\end{tabular}

\section{Results}

Table IV shows the Dispatch results obtained using the Simultaneous Optimization Algorithm for the 14 hour of the delay load diagram.

Figure 3 presents the Evolution of the total cost related to the acquisition ancillary services for the 24 hours of the delay load diagram. 


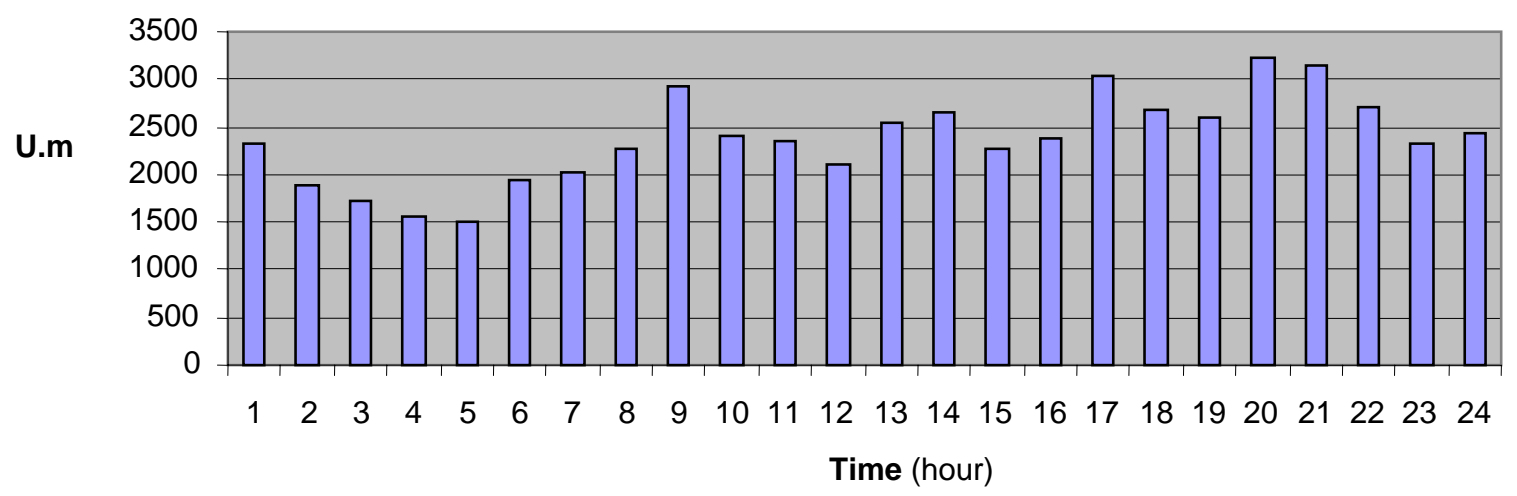

Fig. 3. Evolution of the total cost related to acquisition ancillary services

TABLE IV. - Dispatch results obtained using Simultaneous Optimization Algorithm

\begin{tabular}{|c|c|c|c|c|c|c|c|c|c|}
\hline \multirow[t]{2}{*}{ Bids } & \multicolumn{2}{|c|}{$\begin{array}{c}\text { Regulation } \\
\text { Down }\end{array}$} & \multicolumn{2}{|c|}{$\begin{array}{c}\text { Regulation } \\
\text { Up }\end{array}$} & \multicolumn{2}{|c|}{$\begin{array}{c}\text { Spin } \\
\text { Reserve }\end{array}$} & \multicolumn{2}{|c|}{$\begin{array}{c}\text { Non-Spin } \\
\text { Reserve }\end{array}$} & \multirow{2}{*}{$\begin{array}{l}\text { Total } \\
\text { MW }\end{array}$} \\
\hline & MW & $\mathrm{Um} / \mathrm{MW}$ & \begin{tabular}{|l|} 
MW \\
\end{tabular} & Um/MW & \begin{tabular}{|l|} 
MW \\
\end{tabular} & $\mathrm{Um} / \mathrm{MW}$ & \begin{tabular}{|l|l|} 
MW \\
\end{tabular} & Um/MW & \\
\hline 1 & 30.0 & 3.7 & 0.0 & 0.0 & 0.0 & 0.0 & 0.0 & 0.0 & 0.0 \\
\hline 2 & 45.0 & 3.8 & 0.0 & 0.0 & 0.0 & 0.0 & 0.0 & 0.0 & 0.0 \\
\hline 3 & 0.0 & 0.0 & 0.0 & 0.0 & 0.0 & 0.0 & 0.0 & 0.0 & 0.0 \\
\hline 4 & 0.0 & 0.0 & 0.0 & 0.0 & 0.0 & 0.0 & 0.0 & 0.0 & 0.0 \\
\hline 5 & 0.0 & 0.0 & 30.0 & 4.3 & 0.0 & 0.0 & 25 & 5.0 & 55.0 \\
\hline 6 & 0.0 & 0.0 & 0.0 & 0.0 & 20.0 & 3.8 & 20.0 & 3.5 & 40.0 \\
\hline 7 & 0.0 & 0.0 & 35.0 & 4.5 & 0.0 & 0.0 & 0.0 & 0.0 & 35.0 \\
\hline 8 & 40.0 & 3.6 & 0.0 & 0.0 & 40.0 & 4.2 & 20.0 & 5.0 & 60.0 \\
\hline 9 & 0.0 & 0.0 & 0.0 & 0.0 & 30.0 & 4.0 & 35.0 & 3.0 & 65.0 \\
\hline 10 & 0.0 & 0.0 & 38.0 & 4.3 & 22.0 & 4.0 & 0.0 & 0.0 & 60.0 \\
\hline 11 & 25.0 & 3.2 & 17.0 & 4.8 & 0.0 & 0.0 & 0.0 & 0.0 & 17.0 \\
\hline 12 & 40.0 & 3.8 & 0.0 & 0.0 & 0.0 & 0.0 & 0.0 & 0.0 & 0.0 \\
\hline 13 & 30.0 & 3.8 & 0.0 & 0.0 & 0.0 & 0.0 & 0.0 & 0.0 & 0.0 \\
\hline 14 & 0.0 & 0.0 & 0.0 & 0.0 & 0.0 & 0.0 & 0.0 & 0.0 & 0.0 \\
\hline 15 & 0.0 & 0.0 & 0.0 & 0.0 & 0.0 & 0.0 & 0.0 & 0.0 & 0.0 \\
\hline 16 & 40.0 & 3.7 & 30.0 & 4.5 & 0.0 & 0.0 & 0.0 & 0.0 & 30.0 \\
\hline $\begin{array}{l}\text { Total } \\
\text { MW }\end{array}$ & \multicolumn{2}{|c|}{250} & \multicolumn{2}{|c|}{150} & \multicolumn{2}{|c|}{112} & \multicolumn{2}{|c|}{100} & 612 \\
\hline $\begin{array}{c}\text { MP } \\
\text { Um/MW }\end{array}$ & \multicolumn{2}{|c|}{3.8} & \multicolumn{2}{|c|}{4.8} & \multicolumn{2}{|c|}{4.2} & \multicolumn{2}{|c|}{5.0} & \begin{tabular}{|c} 
Total \\
Um
\end{tabular} \\
\hline $\begin{array}{l}\text { Total } \\
\text { Cost } \\
\text { Um }\end{array}$ & \multicolumn{2}{|c|}{950.0} & \multicolumn{2}{|c|}{720.0} & \multicolumn{2}{|c|}{470.4} & \multicolumn{2}{|c|}{500.0} & 2640.4 \\
\hline
\end{tabular}

\section{Conclusion}

This paper presents different options for the electricity market design that allows to obtained competitive prices and settling Ancillary Services. It also discusses problems and potential solutions associated with the competitive electricity market. A Simultaneous Optimization Algorithm is described to optimize the Active Power Reserves in a competitive environment. In this mathematical formulations are underlined the advantages, drawbacks and the application fields. In order to illustrate the mathematical application of the Simultaneous Optimization Algorithm it was study and analyse the delay load diagram of Portuguese electric power system.

\section{References}

[1] Flynn M., Sheridan W., Dillon D. and O’Malley J.(2002), "Reliability and Reserve in Competitive Electricity Market Scheduling”, IEEE Transactions on Power Systems, Vol. 15, No. 2, pp:483-490 May 2000.

[2] M. Ilic, F. Galiana and L. Fink (Eds.), "Power Systems Restructuring: Engineering and Economics”, Kluwer Academic Publishers, 1998.

[3] CIGRE Task Force 38.05.07, "Methods and Tools For Costing Ancillary Services”, CIGRE Publication, June 2001.

[4] Hirst, Eric and KIRBY, Brendan. "Ancillary Service Details: Operating Reserves”; ORNL/CON-452. Tennessee: Oak Ridge National Laboratory, November, 1997.

[5] Harry Sing, Alex Papalexopoulos, "Competitive Procurement of Ancillary services by an Independent System Operator"; IEEE Transactions on Power Systems, Vol. 14, No2, pp:498-504 May 1999.

[6] Flynn M., Sheridan W., Dillon D. and O'Malley J.(2002), "Reliability and Reserve in Competitive Electricity Market Scheduling”, IEEE Transactions on Power Systems, Vol. 16, No. 1, pp:78-87 February 2002.

[7] Zammit, M., Bolton, A., Hill, D. J. and Kaye, R. J., Designing Ancillary Services Markets for Power Systems Security, IEEE Transactions on Power Systems, Vol. 15, No. 2, pp. 675-680, May 2000.

[8]B. Kirby and E. Hirst "Maintaining System Blackstart in Competitive Bulk-Power Markets,” Proceedings of the American Power Conference, Vol. 61, Chicago, IL, April 1999

[9] B. Kirby and E. Hirst, “Ancillary services detail: Voltage control” Oak Ridge National Laboratory Technical Report, December 1997, ORNL/CON-453.

[10] Hirst E., Maximizing Generator Profits across Energy and Ancillary Services Markets, Tennessee, Oak Ridge National Laboratory, Mar. 2000.

[11] Y. Liu, Z. Alaywan, M. Rothleder, S. Liu, M. Assadian, “A Rational Buyer's Algorithm Used for Ancillary Service Procurement”, IEEE/PES Winter Meeting, Singapore, Jan. 23 -27, 2000.

[12] Papalexopoulos, A. and Singh, H., "On the Various Design Options for Ancillary Services Markets", $34^{\text {th }}$ Annual Hawaii International Conference on System Sciences, Maui, Hawaii, pp. 798-805, Jan. 2002. 